\title{
Cash or Kudos: Addressing the Effort-Reward Imbalance for Academic Employees
}

\section{John E. Hamilton}

Division of Health Research, Lancaster University

\begin{abstract}
This paper reports the findings of a study into the factors influencing psychological wellbeing of academic staff working in a UK Higher Education Institution. The study utilised the EffortReward Imbalance (ERI) model as a framework to examine the balance between the effort academic staff commit to their work and the reward they receive in relation to the model's 3 reward systems: remuneration, career progression and self-esteem. This study utilised qualitative methodology to investigate the experiences of academic staff engaged in predominantly teaching activities $(\mathrm{n}=39)$. In particular the focus groups considered the factors affecting the effort they commit to their work and the characteristics of work that help them feel rewarded. This allowed consideration of the ERI model's reward systems and exploration of a wider range of reward systems within an academic context.

The findings reinforce the use of the ERI model for evaluating factors that influence the wellbeing of academic staff, providing insight into the extrinsic effort that academic staff commit to work as well as recently evolved demands from student expectations and learning capability. Informal reward mechanisms, relating to student interaction and pedagogical impact were found to have a prominent effect in helping academic staff feel rewarded for their work. This provides a possible explanation for academic staff overcommitment to their work in order to maintain informal sources of reward, in the absence of more formal institutional mechanisms. The limitations and implications for future research and practice, including possible interventions to restore effort-reward imbalance for academic staff, are discussed.
\end{abstract}




\section{Effort-Reward Imbalance in Academic Employees}

Keywords: effort-reward imbalance; overcommitment; academic staff; stress; psychological wellbeing 
As a sector, Higher Education accounts for only 163 of the UK's 2.4 million business enterprises (Office for National Statistics, 2015) and as such might not be foremost in the minds of workplace policy makers. However it makes a significant contribution to the UK economy, generating $£ 73$ Billion of output equating to $2.8 \%$ of GDP, and supports around 750,000 full time equivalent jobs, around $2.7 \%$ of total UK employment (Universities UK, 2014). For academic staff employed in a sector that historically provided a low stress working environment (Argyle, 1998) the mass participation expansion of higher education in the 1990's and 2000's significantly altered the content and context of academic work. This was the result of a global expansion of Higher Education participation, driven by a range of factors including state policy, economic growth, urbanisation and expansion of the middle classes (Marginson, 2016). As a result, the global gross tertiary enrolment ratio, a measure of high education participation, increased from around 10\% in 1972 to 32\% in 2012 (UNESCO, 2015). In the UK, enrolled student numbers increased by around 50\% from the mid 1980's to the early 2000's with little or no change in staffing resources (Doyle \& Hind, 1998). Kinman's review (2006) of the psychological wellbeing of academics working in UK Higher education Institutions (HEIs) found that student to staff ratios had increased from 16:1 in 2001 to 18:1 in 2004. This was coupled with reduced levels of job security resulting from a high proportion of academic staff being employed on temporary or fixed term contracts; around $50 \%$ by 2004 (Higher Education Statistics Agency, 2004). More recently, surveys of UK academic employees working in higher education in 2012 (Kinman, Wray, \& Court, 2012) and 2014 (Kinman \& Wray, 2015) showed a widening and worsening gap in a range of stressor categories between the two survey timepoints, with evidence of poorer working relationships, increased levels of psychological distress, and declining work-life balance. More widely the impact on the health of academic staff during this period was examined extensively by studies in HEIs in the UK (see Abouserie, 1996; Kinman et al., 2006), the US (see Barnes, Agago, \& Coombs, 
1998; Blix, Cruise, Mitchell, \& Blix, 1994), South Africa (see Barkhuizen \& Rothmann, 2008; Rothmann \& Jordaan, 2006) and Australia (see Gillespie, Walsh, Winefield, Dua, \& Stough, 2001; Winefield et al., 2003). Whilst there are important contextual differences between the delivery of HE in different countries, influenced by factors such as marketisation and level of state funding, these studies identified similar findings in terms of the impact of the intensification of academia on the psychological wellbeing of those working within it.

\section{Psychological Wellbeing of Academic Staff}

Successive studies have identified a number of factors that influence the psychological wellbeing of academic staff, including reward and recognition, time constraints, departmental influence, professional identity and student interaction (Gmelch, Wilke, \& Lovrich, 1986), lack of research funding, workload and poor management practice (Gillespie et al., 2001), participation in decision making (Biron, Brun, \& Ivers, 2008), career progression (Kinman, 2001), and administrative burden (Kinman \& Jones, 2003). Beyond the working environment, the spill-over of work into the home life of academic staff has been found to be a common occurrence, with many spending evenings and weekends undertaking work or thinking about work (Kinman \& Jones, 2008c). Whilst detrimental to the psychological wellbeing of academic staff the unpaid nature of this workload arguably contributes to institutional efficiency targets. Following the drastic change that higher education in the UK underwent in the decade to 2004, it changed again in the following decade. Pressure on HEIs to perform has increased as a result of independent quality assurance checks (Quality Assurance Agency, 2015), research frameworks (Higher Education Funding Council for England, 2014), international student recruitment pressures (Ross, Grace, \& Shao, 2013; Szekeres, 2010) and financial constraints (Jones, 2015). In response many HEIs have adopted a more short-term, results-driven approach, replacing stewardship mechanisms of individual performance management, focussed on delivery of long-term outcomes through autonomy and shared leadership, with 
agency mechanisms that involve higher levels of monitoring and control (Franco-Santos, Rivera, \& Bourne, 2014). Academic workers used to working with a high level of independence and job autonomy (Egginton, 2010) therefore had to adjust to the implementation of private sector style business practices that have replaced collegiality with a more transparent approach centred on accountability and responsibility (van den Brink, Fruytier, \& Thunnissen, 2013). The move away from collegiality arguably then impacts on wider group goals, such as teaching excellence, as academics are driven to focus on individual targets such as research output. When combined with the efficiencies yielded through increased levels of unpaid academic overtime, this provides a sequence of natural barriers to the prioritisation of academic staff psychological wellbeing above wider institutional operational and commercial targets. This situation was further compounded for academic staff working in United Kingdom Higher Education Institutions through increased pressure from students as a result of the higher tuition fees introduced in 2012 (Saul, 2014).

Yet recent changes in academia have not been exclusively negative. In England, student recruitment has levelled out as the impact of higher tuition fees and government student number caps have limited undergraduate recruitment (Howse, 2014). In addition, numbers of academic staff with teaching or part teaching responsibilities has increased (figure 1), resulting in a consistent improvement in student-to-staff ratio over the same period. Combined with this has been an increase in the proportion of academic staff employed on open-ended or permanent contracts from $64 \%$ in $2004 / 5$ to $70 \%$ in $2014 / 15$. As a result 28,535 more academics were on these more secure forms of contract over that time frame, although many more remain employed on a fixed term basis (Higher Education Funding Council for England, 2016).

Whilst this mitigates two important stressors for academic staff, wider changes to teaching delivery and the commercialisation of higher education have increased the pressure on academics. As a result academic staff remain less satisfied with their working hours, their pay 
and career progression opportunities, whilst still retaining an intrinsic satisfaction with the role itself, through their regular interaction with students, the opportunity to use their initiative, and intellectual stimulation from the subject (Kinman \& Jones, 2008c). However, these effects predate the recent changes in UK higher education, particularly the move to more marketised, customer-driven provision, providing an opportunity to consider how these changes impact of academic staff wellbeing.

The application of theoretical psychological wellbeing models to academic staff has considered the three classic models; Job Demands-Control (Karasek, 1979), Job Demands-Resources (Demerouti, Bakker, Nachreiner, \& Schaufeli, 2001) and Effort-Reward Imbalance (Siegrist, 1996). The need to go beyond simply considering job content has led researchers to consider in particular the latter two models. However, in relation to the study of professional workers, and academic staff in particular, the Effort-Reward Imbalance model gives consideration to how an individual's level of commitment to their work has the potential to impact on their psychological wellbeing. Academic staff have been found to have wide ranging role responsibilities (Winter \& Sarros, 2002) and struggled to maintain a satisfactory work-life balance (Doyle \& Hind, 1998). As such it has been suggested that, in this context, the EffortReward Imbalance model provides a particularly relevant framework to examine job stress (Kinman, 2016; Kinman \& Jones, 2008b). As such it was chosen as the framework with which to investigate the academic working life in this study.

\section{Effort-Reward Imbalance and Overcommitment}

The Effort-Reward Imbalance (ERI) model has become an established framework for considering the social exchange of work and reward in paid employment. The model proposes that the reciprocal arrangement of receiving adequate reward for the effort put into work should be in balance (Siegrist, 1996) such that where an individual perceives a lack of reciprocity, characterised by high effort - low reward working conditions, this leads to a state of emotional 
distress (Siegrist, Falck, \& Joksimovic, 2005). The model distinguishes between extrinsic, situational components and intrinsic, personal components of effort and reward, positing that it is these components in combination that determine health outcomes. Work factors, such as job demands and task autonomy, mismatched with level of reward, transmitted to workers through remuneration, career progression and self-esteem, provide the extrinsic components of the imbalance. The intrinsic component is expressed through the concept of overcommitment, where workers demonstrate a "set of attitudes, behaviours, and emotions that reflect excessive endeavour combined with a strong desire for approval and esteem" (Tsutsumi \& Kawakami, 2004, p2336). Overcommitted workers are characterised in the model as being at a higher risk of job strain resulting from the non-symmetric effort-reward exchange. As such overcommitment can be considered a risk factor in itself, albeit that the model considers that the strongest effect of overcommitment occurs when individual characteristics driving overcommitment and a structural effort-reward imbalance occur coincide (Siegrist et al., 2004). This proposition has been supported by a number of studies that have detected an interaction effect between effort-reward imbalance and overcommitment (see Allisey, Rodwell, \& Noblet, 2012; Feuerhahn, Kühnel, \& Kudielka, 2012)

Numerous studies have tested the use of the ERI model to determine the effect of effort-reward imbalance on a range of adverse physiological and psychological health outcomes (de Jonge et al., 2001; Siegrist, 1998; Siegrist et al., 2005; Tsutsumi et al., 2005) and organisational outcomes (Avanzi, Zaniboni, Balducci, \& Fraccaroli, 2014; Head et al., 2007). Methodologically, the quantification of imbalance, overcommitment and case cut-off points has been established to facilitate quantitative measurement (Lehr, Koch, \& Hillert, 2010; Siegrist et al., 2004). Whilst the use of quantitative methodology to examine and validate the ERI model has ensured a robust platform for its use and understanding, a dearth of qualitative studies in this area has resulted in a lack of understanding of the lived experiences of those 
experiencing an effort-reward imbalance and/or overcommitment. The few studies that have utilised a qualitative approach, have provided insight towards understanding the reciprocal relationship between effort and reward (Cousins \& Donnell, 2012; Trudel et al., 2009). Quantitative studies have proved effective at highlighting aspects of work that employees find demanding, and as such contribute to the effort side of the equation, without providing much insight into how this is balanced by reward, despite some evidence that reward is potentially more influential than effort in the imbalance (Tsutsumi et al., 2005). Siegrist (1996) originally conceived of two possible scenarios relating to overcommitment; the first group of constrained workers comprise blue-collar workers enduring high levels of effort due to limited reemployment opportunities; the second group of aspiring achievers comprise higher status workers "who for strategic reasons assume the extra work and additional responsibilities to compete for promotion prospects" (Siegrist, 1996, p31). For either group it is possible that overcommitment is an intrinsic character trait (Siegrist, 2001), but it could also be possible that for career-driven workers overcommitment is a matter of personal choice (Kinman \& Jones, 2008a). For academic workers whose working life is characterised by classic indicators of effort-reward imbalance and overcommitment, through long hours, administrative burden, poor remuneration, and lack of career progression, a closer examination of these factors using the framework of the ERI model may help explain their influence on psychological wellbeing.

\section{Study Setting and Objectives}

UK universities can generally be categorised into two broad groups; traditional universities comprising those granted a Royal Charter prior to 1992, including the ancient (founded between c1096-1583), red brick (c1832-1957), and plate glass (c1961-1968) universities, and new universities that were former polytechnics prior to 1992 and were then granted university status. In contrast to traditional universities, new universities tend to be characterised by a predominant focus on teaching over research, focussing principally on more vocationally based 
subjects. For new universities the focus on teaching effects institutional funding that, as a result, becomes more reliant on undergraduate tuition fees rather than research grants.

The current study was undertaken in a large new university in England that has a predominant teaching focus. The University's faculty is structured in a number of schools delivering undergraduate and postgraduate higher education across a range of science, healthcare, engineering, arts, humanities, business, education and technology subjects. Analysis of the University's staff satisfaction survey for the year 2014 indicated that academic staff at the Institution had a $20.9 \%(\rho<.05)$ lower mean response across all questions compared to professional and support staff. The survey results indicated that academic staff enjoyed contact with students, felt their work was varied, interesting and gave them a sense of personal achievement, and felt valued by students. However, their responses indicated they did not have a good work-life balance, had too many conflicting demands and were required to undertake too many tasks they consider unimportant. To explore this further, this study was commissioned by the University's Human Resources leadership team to better understand the factors that influence the wellbeing principally of teaching academics' wellbeing, particularly related to the relationship between the effort they commit to their work, and how they felt rewarded for this effort. Its aim was to explore the lived experiences of academic workers working in a sector characterised by fundamental changes in funding, marketisation and student expectations. The study therefore had the following objectives:

1. To provide an insight into aspects of academic workload and working conditions that place demands on academic staff;

2. To provide an insight into aspects of academic work and social interactions that help academic staff feel rewarded;

3. To investigate what drives academic staff commitment to work, particularly their students and the organisation; 
4. To identify possible interventions to help restore effort-reward imbalance for academic staff.

\section{Methods}

The study used qualitative methodology to provide the basis to examine the lived experiences of academic staff at the university. This comprised the use of focus groups to collect the views of academic staff on aspects of their work they found demanding and rewarding.

\section{Sample}

A purposive sample of participants was constructed through volunteers recruited through academic managers across each of the University's schools that had the highest and lowest levels of wellbeing and job satisfaction indicated by the 2014 staff satisfaction survey. This would provide a contrast between academic staff that had high and low levels of wellbeing and satisfaction. The final sample was selected to ensure a representation of the variety of academic roles, gender $($ Female $=53.8 \%$, Male $=46.2 \%)$ and length of service $(\mathrm{M}=10.1$ years, $\mathrm{SD}=8.5$ years) present in the faculty. All participants gave informed written consent to participate in the study.

\section{Focus groups}

Eight focus groups were initially undertaken, with eight participants invited to each group. Constraints in academic staff timetabling resulted in group sizes between two to six with the role and demographic profile included in Table 1. A full range of academic roles was represented in the focus groups; senior lecturer $(n=22)$, principal lecturer $(n=5)$, professor $(n=2)$ researcher $(n=3)$, part-time lecturer $(n=2)$. At the conclusion of these initial focus groups an additional focus group was run with five academic managers from the schools that the participants had been recruited from. 
Focus group data collection allowed participants to share experiences and draw out diverse and shared opinions. A semi-structured approach was used to guide the discussion (Bryman, 2008) with the author facilitating the group. Discussion areas were generally guided by the key components of the ERI model, focussing on aspects of participants work such as job demands and task autonomy and their consequent level of reward such as remuneration, career progression opportunities and feedback mechanisms. Participants were first asked to identify the aspects of their job that they find most rewarding, and those they find least rewarding. Once each participant had answered, the discussion followed on to explore the initial answers, examining shared and diverse views and opinions within the group. Discussion topics that emerged were introduced into subsequent groups to enable cross group comparison. Discussions naturally evolved into aspects of the job that represented effort, such as workload, working hours, administrative burden and bureaucracy, and those that participants found rewarding, such as student interaction, peer interaction, job autonomy and subject interest. To conclude the focus group, participants were asked to identify one thing that would help them feel more rewarded for the work that they do. All participants made an active contribution to the groups, providing views and opinions across a range of subjects relating to their experience of working in academia. The focus groups took between 38 and 65 minutes, with each being audio recorded and transcribed verbatim. Following transcription, the participant identities were anonymised through the allocation of pseudonyms to protect their confidentiality.

\section{Data analysis}

The transcripts were analysed using NVivo10 qualitative analysis software produced by QSR International. The data analysis was guided by the five-step process offered by Pope (2000) of familiarisation, development of the thematic framework, followed by coding, charting and mapping. Following initial review of the transcripts a priori coding framework was used to structure the initial coding. This was iterated and restructured as emerging themes were 
identified in the coding process with new codes and sub-codes developed through the coding process (Bryman, 2008). All of the transcripts were coded, however data saturation in terms of code creation and repetition was achieved before all the data had been coded. Each transcript was then reviewed to ensure that new codes were coded back in. It became clear that many views expressed had contextual meaning in relation to perceptions of reward, as such further coding of passages, comments, and phrases was undertaken to identify their context either as a reward enabler, a factor that helped participants feel rewarded, or as a reward disabler, a factor that inhibited participants feeling rewarded.

Once coding was complete the data was charted and mapped using three techniques in NVivo10 to help identify the patterns, clusters and linkages in the data (Ritchie, Spencer, \& O'Connor, 2003). First, coding matrices were used to examine the profile of the codes in relation to their being reward enablers or reward disablers. This allowed clear emerging themes to be identified in the data,including informal reward mechanisms, teaching effort and autonomy, career progression, and poor performance impact. Within these themes a number of prominent codes were identified. The second stage was to triangulate these emerging themes using the NVivo cluster analysis tool. This provided confirmation of the broad themes identified in the first stage, and highlighted additional codes to be included within those themes. At this stage teaching effort and autonomy theme was split into two themes to enable more precise analysis. The final stage was to construct a framework matrix for each theme to allow the individual comments and opinions coded to each group of thematic codes to be compared and contrasted, summarised and memorable quotations identified (Silverman, 2010). This provided a thematic structure to report the narrative emerging from the focus group discussions. 


\section{Results}

Five themes were identified as influencing the effort-reward balance of academic staff, as summarised in figure 2. The informal reward mechanisms resulting from student interaction and pedagogical impact together with the autonomy they have in their role are the primary sources of reward and job satisfaction for academic staff. This is countered by a high teaching effort they perceive as being driven by non-essential administrative tasks, unnecessary bureaucracy, and high email volume, coupled with long working hours during teaching weeks. The poor performance impact of individual colleagues impacts on feelings of reward and fairness, with a need to more clearly define pathways for career progression and mechanisms for recognising teaching excellence

\section{Informal reward mechanisms}

Student interaction is at the centre of the mechanisms that academic staff find rewarding. The face-to-face contact in the classroom, particularly with small student groups, builds personal relationships and allows them to interact with students and their subject. This relationship provides the basis for the most important reward mechanism for academic staff, seeing the impact of their pedagogy as students' progress. Frequently academic staff identify the 'light bulb moment' when students begin to understand a particular theory or apply a complex principle, as the most rewarding aspect of their work. These moments are the reward for the planning and preparation that academic staff put into lectures, seminars and practical sessions, allowing them an opportunity to share their own passion for the subject. Those light bulb moments then become more sustained as students progress through modules towards graduation.

\footnotetext{
"I like it when students start to have insights that go beyond what I have seen in the text... you get a frisson of excitement that they have actually discovered something that you didn't
} 


\section{Effort-Reward Imbalance in Academic Employees}

see there or that wasn't part of what you were trying to aim for. That's wonderful"

Nannette, Senior Lecturer

The progression of weaker students, those that struggle with the move to higher education, provides both a challenge and a source of reward for academic staff. Beyond teaching, academics take on as much a mentoring role with these students, guiding them more closely to help them improve and develop. By the end of a module this becomes a source of reward where students improved and gained confidence in the subject. Seeing students graduate becomes a focal point for that progression. Graduation provides a public celebration of the contribution academic staff have made to their students' achievements, a culmination of the journey they have been on together.

"What I found most rewarding about the job is the week in July when our students graduate. I think that's fantastic because you look at them and you think, "Gosh, I remember you when you were in your first year," and particularly, the ones that you think in first year, they're not going to do so well and then they come out, they really upped the game, they really engaged with what they're doing and they come out with a really good degree. And it's just the look in their faces and their families and friends. I think there's nothing nicer and more rewarding than that." Diane, Principal Lecturer

However this pedagogical impact is also visible throughout the semester in teaching sessions where students are developing their understanding. As they progress to their final year this is illustrated in students engaging in debate, developing practical skills, designing sessions, and working on final year projects. The sense of reward academic staff feel continues as they see the growth in the knowledge and skills students develop as they progress through their degree, ultimately equipping them for the world of work or further study. Frequently this is expressed as their desire to make a difference or have an impact, as such the mechanisms for seeing this progression are critical for academic staff feeling rewarded for what they do. What is evident 
is that these reward mechanisms are primarily informal; resulting from the interaction academic staff have with their students, their subject, and their peers. Whilst more formal student feedback mechanisms do exist, such as student satisfaction surveys or module reviews, it is the informal feedback that academic staff seem to value the most. Comments following teaching sessions provide real-time feedback on the value of the session, and directly results in those staff feeling rewarded for their planning and preparation.

\footnotetext{
"The reward for me is not when the student says, "Oh, I enjoyed the session." It's not so much about the enjoyment of the session. It's nice that they have that. But whether or not they actually feel they've learned something and come out of it like "That was a great lecture, I feel like I really understand that topic now," or "I had a really engaging seminar". That for me, that's one of the major parts of the job that I really kind of feel that getting some reward from putting the hours in." Iain, Senior Lecturer
}

In addition to student feedback, the interaction that academic staff have with their peers provides another important sense of reward and satisfaction. The collegiality of colleagues translates into an important source of social support and social reward for academic staff, creating the opportunity to share knowledge and ideas, develop lines of thought, and receive feedback and praise on good work. Close colleagues are considered by many to be good friends whom they often socialise with outside of work. Peer feedback is a valued source of support, although opportunities are limited by time pressures and timetabling constraints for this to become more structured.

\section{Autonomy}

Academic staff value the high degree of autonomy they have to teach their subject and design modules their own way. This intellectual autonomy provides an important outlet for creativity and drives the feeling of reward when students provide positive feedback and achieve progression. This provides a flexible approach that appears to accommodate a variety of ways 
that academics think about and engage in their subject. In contrast, the constraints in the way that working time is structured, compounded by a workload that academic staff often feel is influenced by large amounts of administrative work and bureaucratic processes results in a lack of perceived organisational autonomy. This appears to create an autonomy conflict where academics value the freedom to think and reflect, but often work in an environment where the opportunities to do so are limited.

\begin{abstract}
"There are times that I find quite frustrating that I can't be as free a thinker and develop what I want to be because of all the other constraints that we've got. It also leaks into that creativity because the constraints become so great that the one bit that you really want to think and explore and work with gets crushed by all the other things that are happening."
\end{abstract}

\title{
Felicity, Senior Lecturer
}

This allocation and management of time is an important component in this conflict. In particular the need to balance teaching workload with research and enterprise activities is particularly demanding, where academic staff often work at evenings and weekends. With research outputs being critical to career progression these demands place additional pressure on academic staff who are, as a result, frustrated at the lack of available time for this area of activity. Not surprisingly academic staff identified the provision of time, particularly protected space within their work allocation, as being of value. This was described by one participant as 'white space' time without distraction that would provide opportunity for research, curriculum development and reflection.

Like many HEIs, academic time at this university is allocated using a deployment model, which as well as allocating teaching responsibilities apportions time for other activities - notably research time and other scholarly activities. However as teaching delivery methods have changed with the advent of multi-modal delivery across a number of face-to-face and virtual media there is evidence that deployment models have not kept up with the increasing time 


\section{Effort-Reward Imbalance in Academic Employees}

commitments these methods required. As a result, academics felt that the workload resulting from a large number of 'invisible tasks' were not accurately captured in their deployment.

"IIf] you look at their timetable and look at the teaching they're doing and think, "Why are they complaining? They've got, what, 12 or 13 hours of contact, why are they complaining?" And yet, if you follow them around, you would see why they're so exhausted. So I do think we need a better way of capturing that to get a sense of the enormity of the task." Sophie, Principal Lecturer

\section{Teaching Effort}

Academic workload is driven by a number of other factors beyond teaching workload. Where these are perceived by participants to be of little value, waste time, or appear to obstruct teaching activities academics exhibit a frustration. Large amounts of administration, unnecessary bureaucracy and high volumes of email were frequently cited as the least rewarding aspects of their work. A number of examples were given of processes that appear over-engineered and as a result take longer than they should.

"The bureaucracy is really kind of, in some ways, holding us back. And it's just a frustration that you try and move something forward and it's just a simple thing that needs to be done but say you have contact with three or four different people and several meetings and then eventually something gets done, if that is the outcome, or you find out it can't be done and you're like, 'Well, if I had just been told that at the start, I would have saved all of this time.' That's the frustration." Roger, Senior Lecturer

Similarly, high volumes of email, both from staff and from students, absorb a significant proportion of academic staff time. This provides a challenge in prioritising important tasks and deadlines, with email being an example of a task frequently done at evenings and weekends. Student emails often relate to information that is readily available in the course handbook, yet 


\title{
Effort-Reward Imbalance in Academic Employees
}

the nature of the personal relationship with the tutor results in them being the first point of contact.

\begin{abstract}
"It is endless emails, endless emails. Actually it means that there's so much emailing to do that you end up not being able to make room for the things that you have in your day. And you know, students expect you to respond to emails fairly promptly. The prompter you are, then the more likely they are to follow it up with another one. So you can actually just end up getting engaged in the to-ing and fro-ing of email conversations for three hours and then you've got so much other stuff to fit into your day." Nanette, Senior Lecturer
\end{abstract}

The changing nature of students also places increasing levels of demand on academic staff. The increase in student fees has created a demanding consumer mindset amongst students. The transparent nature of feedback provision for items such as consumer goods and travel means students are demanding in the standards they expect for the fees they are paying.

\footnotetext{
"It's a product they feel that they're buying sometimes and if we don't deliver, then they write... it's like writing a review on Amazon. So they give you bad feedback in that sense but in a very kind of product-centred sense. And I think that they lose a grip on the amount of independent learning that they're supposed to do, how much it's the person's responsibility for their degree." Sara, P/T Lecturer
}

\begin{abstract}
Aligned to the consumer mindset is an apparent trend reported by participants for students to become less independent in their learning style. This manifests itself in teaching having to be more structured and defined as the learning becomes more prescribed and less about applying principles and theories. Opinions varied on the cause of this, whether it is directly caused by the demanding consumer mindset, or as a result of changing teaching delivery in secondary education, or a combination of the two. Either way the impact on academic staff can be significant.
\end{abstract}




\section{Effort-Reward Imbalance in Academic Employees}

"The one-on-one isn't about just wanting contact time on an individual basis, it's about them wanting you basically to do it for them. Give me a structure that I can basically just have a structured answer and I can just input people's names and places. It's like filling the gaps, and if we don't get that, well it's been a poor module." Rebecca, Senior Lecturer

\section{Poor performance impact}

More effective management of the poor performance of colleagues was identified by a number of academic staff as a way of improving how rewarded they would feel for their own contribution. This went beyond the fairness and equitability of one person doing less work than others, instead relating to the effect this has on the recognition of their own pedagogical impact within a wider subject group. Where individual underperformance adversely affects the quality of students' experience this can be reflected in student satisfaction survey outcomes that then represent the contribution of all academic staff on a particular course.

\section{"I get really frustrated with colleagues that I don't perceive are having a good enough impact on the students or the student experience isn't there. And I understand exactly why, their rewards are on research and they're focused on their research. "Iain, Senior Lecturer}

\section{Career progression}

Discussion on reward highlighted the frustrations that teaching academics have with the recognition mechanisms for teaching, the teaching career pathway, and progression challenges. Like many HEIs career progression for academics at this university has two avenues; a management route and a research route. Both routes provide their difficulties, whilst management opportunities are limited and result in a move away from teaching, research opportunities require a body of research output that is challenging to put together for a teaching academic. For teaching academics who want to continue teaching this limits career progression opportunities. 


\section{Effort-Reward Imbalance in Academic Employees}

"I'm focused on the student experience yet I feel as a senior lecturer I'm being held back in where I can go in my career because there is no equal reward for people that want a really good student experience and focus on that. The reward is for researchers." Adrian, Senior Lecturer

What teaching academics desire is a structured career progression route that recognises teaching excellence, and gives them an opportunity to share their pedagogical practice. The paradox with the current progression route is that a promotion for excellent teaching, either to a management role or into research, results in that person doing less teaching. An alternative progression pathway was identified by both academic staff and the academic managers; the recognition of teaching excellence through a professorial route for teaching, where an individual has demonstrated excellence in facilitating learning and influencing beyond the classroom.

"A professorship for teaching fellowships. Very few universities actually reward teaching. No progressions for teaching, if you look at the way the university structures are, there are no promotion routes to teaching. Basically, lecturer, senior lecturer end of story." Seb, Senior Lecturer

"[Universities] need to grapple with a teaching focussed professorial role, a pedagogically based excellent teacher who is a professor, who isn't publishing at four star necessarily but being really good in the classroom." Vanessa, Academic Manager 


\section{Discussion}

This qualitative study used the ERI model to provide a framework to examine factors influencing the effort that academic staff commit to their work and the aspects that help them feel rewarded. Despite the changing nature of academia in recent years many of the extrinsic effort factors reported by the study's participants align to those identified in earlier studies in the sector, such as long working hours, too many administrative tasks, and limited time availability (Kinman \& Jones, 2008b), role overload and poor feedback (Winter \& Sarros, 2002), poor career progression pathways (Smith, Crookes, Else, \& Crookes, 2012) and lack of academic support functions (Gillespie et al., 2001). The rich, qualitative insight provided by this study complements the findings of Kinman's (2016) quantitative study of effort-reward imbalance in UK academics, particularly that academic employees committing more effort to their work suffered poorer mental health, less job satisfaction and were more intent on leaving their institution. The findings also support the importance of autonomy to academic staff (Boyd et al., 2011; Egginton, 2010) whilst also identifying a tension in the autonomy that academics have in their role where they value the intellectual autonomy to teach a subject in a particular manner but feel restricted by a lack of organisational autonomy related particularly to the allocation of time, teaching facilities and administrative processes. This supports the findings of other studies that identified a relationship between autonomy, work motivation and wellbeing (e.g. Lynch \& O'Mara, 2015; Olesen, Thomsen, \& O’toole, 2015; Van Yperen, Wörtler, \& De Jonge, 2016), with the organisational-intellectual tension perhaps explaining why, for academic workers, autonomy is important factor in their psychological wellbeing. The study seems to provide enlightening insight to the reward component of the ERI model. Firstly, it is worth noting one aspect of the extrinsic reward component that was hardly mentioned by participants in the current study, that of pay. With academic pay stagnating (Grove, 2016) it is perhaps surprising that it did not feature more prominently in a discussion 
on reward. However, pay in UK HEIs is largely governed by national bargaining which results in consistent pay grades across the sector with little room for market forces to take effect. As such the lack of influence academics have directly on pay perhaps explains its lower importance in relation to reward. Related to pay, however, the lack of a structured career progression pathway for teaching was an aspect of reward that academic staff found frustrating. Academic staff with a passion for teaching are in the paradoxical situation where the available promotion routes result in doing less of the aspect of work that they both excel at and find most rewarding. Coupled with the teaching time constraints that restrict the opportunity to deliver research outputs, this results in many academics being stuck in the same teaching grade for many years, compounding their pay stagnation.

In contrast the third extrinsic reward component, self-esteem, offers a powerful source of reward for academic staff. Participants talked about their students with a passion and commitment that suggests this is the predominant factor in their effort-reward equation. Seeing the impact of their pedagogy as students progress through their higher education journey provides a direct, unfiltered, real-time source of reward and recognition for the planning, preparation, and support they give to their students. Whilst this is not without its problems, as participants in this study identify, $21^{\text {st }}$ century students appear to be more demanding and less independent in their learning style. Potentially this results in more demanding students requiring more basic forms of support, reducing the higher levels of perceived pedagogical impact. It is evident that these informal reward mechanisms are what matters most to many academic staff. It also perhaps explains why many academics overcommit to their work, often working long hours at evenings and weekends, driven by a desire to deliver the best possible learning experience for their students. This in turn then translates into a strong source of reward. Considering then the two groups of employees that Siegrist (1996) postulated might have high prevalence of overcommitment, the constrained workers and the aspiring achievers, it becomes 
evident that academic workers potentially fit both groups. They work in a relatively niche employment market where employment opportunities are limited by academic speciality and location. The increasing transparency and accountability that the introduction of modern business practices into HE (van den Brink et al., 2013) has placed many in a situation where, by historic standards, work pressure has substantially increased. Similarly, for ambitious academics the career progression pathways, particularly those leading into research, require academic staff to overcommit in the delivery of research outputs in to help fulfil career ambitions. To those two groupings, however, can perhaps be added a third; a group of feedback seekers comprising overcommitted teaching academics striving to deliver a high quality learning experience for students in order to generate an important source of reward through student interaction and pedagogic impact. In this scenario, the informal reward mechanisms identified in this study perhaps offer some explanation for the counterbalancing effect of reward on the adverse outcomes related to overcommitment exhibited through excessive involvement and inability to disengage (Kinman, 2016).

All of which perhaps explains why academics' perceptions of reward are impacted by instances of poor performance by academic colleagues. Previous studies have established a relationship between relational justice, a component of the organisational justice model (Colquitt, Conlon, Wesson, Porter, \& Ng, 2001; Greenberg, 1990), and effort-reward imbalance suggesting that both models "violate reciprocity in contractual exchange and unfair treatment by supervisors" (Head et al., 2007, p438). In reality, however, the explanation might be more straightforward, that individual underperformance is simply an obstacle in the informal recognition pathway that helps academic staff feel rewarded for delivering high quality learning.

The study highlighted that work-life balance can be influenced by both reward enablers and by reward disablers. This implies a 'double whammy' effect on work-life balance as teaching effort increases and autonomy decreases through the combined effect of higher workload and 
increased bureaucratisation. As well as the pure effect on available time, the application of a spillover effect has been identified both generally (Bakker, Demerouti, \& Burke, 2009; Greenhaus \& Beutell, 1985) and in an academic setting (Kinman \& Jones, 2008c). This describes how the interrelated and interdependent experiences of work and family life spillover to impact on each other (Adams, King, \& King, 1996; Warr, 1987; Williams \& Alliger, 1994), in this instance through directional Work-Family Conflict (Netemeyer, Boles, \& McMurrian, 1996). Whilst it is understood that finite resources are available to cope with the demands of work and family life (Edwards \& Rothbard, 2000; Kendall \& Muenchberger, 2009) such that their erosion by one has a detrimental effect on the other, this study also highlights the erosion of a positive reward mechanism (autonomy) through a reduction in work-life balance.

\section{Practical implications}

The findings of this study provide an opportunity for HEIs to consider how to restore the effortreward imbalance for their academic staff through design of organisational interventions to directly improve wellbeing and job satisfaction, and indirectly improve the quality of their students' learning experience and higher education outcomes. Recognising the power of the informal reward mechanisms described will help inform HEIs on the development of formal reward mechanisms that specifically reward and recognise academic staff contribution and pedagogical impact. For instance, alongside the celebration of student achievements at graduation ceremonies, there could be similar opportunities to recognise the contribution of academic staff to that success. Similarly the introduction of a Teaching Excellence Framework for HEIs in England (Department for Business Innovation and Skills, 2016) may help provide a framework for recognising academic excellence. With autonomy and time being highly valued by academics, HEIs could consider how deployment processes optimise time allocations within teaching workloads to facilitate research, enterprise activity, and reflective practices that will further support career progression, research outputs, and institutional goals. 
Similarly, academic workload models could be reviewed to ensure they reflect the increased preparation and delivery time associated with multi-modal delivery, and minimise the time that academic staff have to interact and engage with non-essential administrative processes. Assisting students to bridge the learning gap between secondary and higher education would reduce demands on academic staff and this could be achieved by enhancing the guidance provided to new students during induction on the independent nature of the learning style required for higher education programmes.

With individual under-performance showing to be a strong influence in the pedagogical impact reward mechanism for academics, HEIs need to ensure that performance management processes are quickly and assertively targeted to avoid an adverse impact on either the student experience or academic reward. Aligned to this is the need to ensure that such systems are designed to evaluate the unique nature of academic work, particularly reflecting the importance of autonomy and, where possible, capture informal feedback from students and peers. Similarly, the career progression routes for teaching academics should be more clearly defined to provide opportunities for advancement that recognise, reward and maintain teaching contribution, as well as promoting wider pedagogical excellence.

\section{Strengths, limitations and further research}

This study has provided a unique insight into the lived experiences of academic staff working in an English HEI. The findings supplement the national and international studies that have considered effort-reward imbalance and overcommitment in this context. Whilst the findings do support many of the aspects of academic work that are believed to influence effort and reward, they also provide new insight into the mechanisms that support those factors; principally the informal reward mechanism. The researcher's own role, a practitioner operating independently of the teaching and research activities of the host organisation, helped ensure that research data was captured and analysed objectively. There are a number of factors that 
limit the generalisability of the findings beyond the sample involved in the study. Despite the themes aligning to those reported in quantitative studies, the views expressed by participants in this study may not be representative of academic staff in other HEIs. Similarly, the study was undertaken in an English post-92 university with a predominant teaching focus, as such effort-reward factors may vary across different types of HEI, particularly those more prominently focussed on research. Even within the study's teaching focus, the study sample had an over-representation of participants working in a Senior Lecturer role, as such care should be taken in generalising the findings across other academic posts. Further research could examine the mechanism of overcommitment in relation to striving for a high quality learning experience and its effect on reward. Similarly, a longitudinal intervention study deploying mixed-methodology would provide evidence and insight into the effectiveness of an ERI model-inspired intervention to restore the effort-reward imbalance for academic staff.

\section{Conclusions}

The findings of this study reinforce the use of the ERI model for evaluating the factors that influence the wellbeing of academic staff. Aspects of academic work related to extrinsic effort, such as working hours, workload, and administrative burden, support the findings of previous quantitative studies. However, the use of qualitative methodology has provided an insight into a number of other factors relating to effort, such as student expectations and capability, and reward, through the impact of poor performance. In particular the strength of informal reward mechanisms related to student interaction and pedagogical impact play an important role in helping academic staff feel rewarded for their work. This goes further in providing a possible explanation for why many academic staff overcommit to their work. Finally, there are a number of practical changes that HEIs can consider to help maintain an effort-reward balance for academic staff, particularly relating to recognition mechanisms, teaching career progression pathways, academic deployment, and performance management. 
Effort-Reward Imbalance in Academic Employees

Mailing address confirmed as

John E Hamilton

Division of Health Research

Lancaster University

Bailrigg

Lancaster

LA1 4YW

United Kingdom 


\section{References}

Abouserie, R. (1996). Stress, coping strategies and job satisfaction in university academic staff. Educational Psychology, 16(1), 49-56. doi:10.1080/0144341960160104

Adams, G. A., King, L. A., \& King, D. W. (1996). Relationships of job and family involvement, family social support, and work-family conflict with job and life satisfaction. Journal of Applied Psychology, 81(4), 411-420. doi:10.1037/0021-9010.81.4.411

Allisey, A., Rodwell, J., \& Noblet, A. (2012). Personality and the effort-reward imbalance model of stress: Individual differences in reward sensitivity. Work \& Stress, 26(3), 230251. doi:10.1080/02678373.2012.714535

Argyle, M. (1998). The Social Psychology of Work. London: Penguin.

Avanzi, L., Zaniboni, S., Balducci, C., \& Fraccaroli, F. (2014). The relation between overcommitment and burnout: does it depend on employee job satisfaction? Anxiety, Stress \& Coping, 27(4), 455-465. doi:10.1080/10615806.2013.866230

Bakker, A. B., Demerouti, E., \& Burke, R. (2009). Workaholism and Relationship Quality: A Spillover-Crossover Perspective. Journal of Occupational Health Psychology, 14(1), 23-33. doi:10.1037/a0013290

Barkhuizen, N., \& Rothmann, S. (2008). Occupational stress of academic staff in South African higher education institutions. South African Journal of Psychology, 38(2), 321-336. doi:10.1177/008124630803800205

Barnes, L. L. B., Agago, M. O., \& Coombs, W. T. (1998). Effects of Job-related stress on faculty intention to leave academia. Research in Higher Education, 39(4), 457-469.

Biron, C., Brun, J.-P., \& Ivers, H. (2008). Extent and sources of occupational stress in university staff. Work: Journal of Prevention, Assessment \& Rehabilitation, 30(4), 511522. 
Blix, A. G., Cruise, R. J., Mitchell, B. M., \& Blix, G. G. (1994). Occupational stress among university teachers. Educational Research, 36(2), 157-169. doi:10.1080/0013188940360205

Boyd, C. M., Bakker, A. B., Pignata, S., Winefield, A. H., Gillespie, N., \& Stough, C. (2011). A longitudinal test of the job demands-resources model among Australian university academics. Applied Psychology: An International Review, 60(1), 112-140. doi:10.1111/j.1464-0597.2010.00429.x

Bryman, A. (2008). Social Research Methods (3rd ed.). Oxford: Oxford University Press.

Colquitt, J. A., Conlon, D. E., Wesson, M. J., Porter, C. O. L. H., \& Ng, K. Y. (2001). Justice at the millenium: a meta analytic review of 25 years of organizational research. Journal of Applied Psychology, 83(3), pp425-445.

Cousins, R., \& Donnell, C. (2012). Nurse prescribing in general practice: a qualitative study of job satisfaction and work-related stress. Family Practice, 29(2), 223-227.

de Jonge, J., Dormann, C., Janssen, P. P. M., Dollard, M. F., Landeweerd, J. A., \& Nijhuis, F. J. N. (2001). Testing reciprocal relationships between job characteristics and psychological well-being: A cross-lagged structural equation model. Journal of Occupational and Organizational Psychology, 74(1), 29-46.

Demerouti, E., Bakker, A. B., Nachreiner, F., \& Schaufeli, W. B. (2001). The job demandsresources model of burnout. Journal of Applied Psychology, 86(3), 499-512.

Department for Business Innovation and Skills. (2016). Success as a Knowledge Economy: Teaching Excellence, Social Mobility and Student Choice. Retrieved from https://www.gov.uk/government/uploads/system/uploads/attachment_data/file/523396 /bis-16-265-success-as-a-knowledge-economy.pdf

Doyle, C., \& Hind, P. (1998). Occupational Stress, Burnout and Job Status in Female Academics. Gender, Work \& Organization, 5(2), 67-82. 
Edwards, J. R., \& Rothbard, N. P. (2000). Mechanisms linking work and family: Specifying the relationships between work and family constructs. Academy of Management Review, 25, 178-199.

Egginton, B. E. (2010). Introduction of Formal Performance Appraisal of Academic Staff: The Management Challenges Associated with Effective Implementation. Educational Management Administration \& Leadership, 38(1), 119-133. doi:10.1177/1741143209351660

Feuerhahn, N., Kühnel, J., \& Kudielka, B. M. (2012). Interaction effects of effort-reward imbalance and overcommitment on emotional exhaustion and job performance. International Journal of Stress Management, 19(2), 105-131. doi:10.1037/a0028338

Franco-Santos, M., Rivera, P., \& Bourne, M. (2014). Performance Management in UK Higher Education Institutions: the Need for a Hybrid Approach. Retrieved from London:

Gillespie, N. A., Walsh, M., Winefield, A. H., Dua, J., \& Stough, C. (2001). Occupational stress in universities: Staff perceptions of the causes, consequences and moderators of stress. Work \& Stress, 15(1), 53-72. doi:10.1080/02678370110062449

Gmelch, W. H., Wilke, P. K., \& Lovrich, N. P. (1986). Dimensions of stress among university faculty: Factor-analytic results from a national study. Research in Higher Education, 24(3), 266-286. doi:10.1007/BF00992075

Greenberg, J. (1990). Organizational justice - yesterday, today, and tomorrow. Journal of Management, 16, pp399-432.

Greenhaus, J. H., \& Beutell, N. J. (1985). Sources of Conflict Between Work and Family Roles. Academy of Management Review, 10(1), 76-88. doi:10.5465/amr.1985.4277352

Grove, J. (2016, 2 June 2016). Management salaries soar as academic pay stagnates, data suggest. Times Higher Education. Retrieved from Management salaries soar as academic pay stagnates, data suggest 
Head, J., Kivimäki, M., Siegrist, J., Ferrie, J. E., Vahtera, J., Shipley, M. J., \& Marmot, M. G. (2007). Effort-reward imbalance and relational injustice at work predict sickness absence: The Whitehall II study. Journal of Psychosomatic Research, 63(4), 433-440. doi:10.1016/j.jpsychores.2007.06.021

Higher Education Funding Council for England. (2014). Research Excellence Framework 2014: The results. Retrieved from London:

Higher Education Funding Council for England. (2016). Staff employed at HEFCE-funded HEIs: Trends and profiles. Retrieved from http://www.hefce.ac.uk/analysis/staff/

Higher Education Statistics Agency. (2004). Resources for Higher Education Institutions. Retrieved from London:

Howse, P. (2014). Higher fees led to $17 \%$ drop in UK undergraduates. Retrieved from http://www.bbc.co.uk/news/education-25761133

Jones, L. (2015, July 23 2015). The perpetual financial crisis of UK higher education. Times Higher Education. $\quad$ Retrieved from https://www.timeshighereducation.com/blog/perpetual-financial-crisis-uk-higher$\underline{\text { education }}$

Karasek, R. A. (1979). Job Demands, Job Decision Latitude, and Mental Strain: Implications for Job Redesign. Administrative Science Quarterly, 24(2), 285-308.

Kendall, E., \& Muenchberger, H. (2009). Stressors and supports across work and non-work domains: The impact on mental health and the workplace. Work, 32(1), 27-37. doi:10.3233/WOR-2009-0813

Kinman, G. (2001). Pressure points: A review of research on stressors and strains in UK academics. Educational Psychology, 21(4), 473-492. doi:10.1080/01443410120090849 
Kinman, G. (2016). Effort-Reward Imbalance and Overcommitment in UK Academics: Implications for Mental Health, Satisfaction and Retention. Journal of Higher Education Policy and Management, 38(5), 504-518. doi:10.1080/1360080X.2016.1181884

Kinman, G., \& Jones, F. (2003). 'Running Up the Down Escalator': stressors and strains in UK academics. Quality in Higher Education, 9(1), 21.

Kinman, G., \& Jones, F. (2008a). Effort-reward imbalance and overcommitment: Predicting strain in academic employees in the United Kingdom. International Journal of Stress Management, 15(4), 381-395. doi:10.1037/a0013213

Kinman, G., \& Jones, F. (2008b). Effort-reward imbalance, over-commitment and work-life conflict: Testing an expanded model. Journal of Managerial Psychology, 23(3), 236251. doi:10.1108/02683940810861365

Kinman, G., \& Jones, F. (2008c). A life beyond work? Job demands, work-life balance, and wellbeing in UK academics. Journal of Human Behavior in the Social Environment, 17(1-2), 41-60. doi:10.1080/10911350802165478

Kinman, G., Jones, F., \& Kinman, R. (2006). The Well-being of the UK Academy, 1998-2004. Quality in Higher Education, 12(1), 15-27. doi:10.1080/13538320600685081

Kinman, G., \& Wray, S. (2015). Stress Survey in Higher Education 2014 Retrieved from https://www.ucu.org.uk/media/6908/UCU-survey-of-work-related-stress-2014--$\underline{\text { summary-of-findings-Nov-14/pdf/ucu_stresssurvey14_summary.pdf }}$

Kinman, G., Wray, S., \& Court, S. (2012). Stress Survey in Higher Education 2012 Retrieved from https://www.ucu.org.uk/stresssurvey12

Lehr, D., Koch, S., \& Hillert, A. (2010). Where is (im)balance? Necessity and construction of evaluated cut-off points for effort-reward imbalance and overcommitment. Journal of Occupational \& Organizational Psychology, 83(1), 251-261. 
Lynch, B. P., \& O'Mara, E. M. (2015). Do Autonomous Individuals Strive for Self-Positivity? Examining the Role of Autonomy in the Expression of Self-Enhancement. Self and Identity, 1-17. doi:10.1080/15298868.2015.1006244

Marginson, S. (2016). High Participation Systems of Higher Education. The Journal of Higher Education, 87(2), pp243-271.

Netemeyer, R. G., Boles, J. S., \& McMurrian, R. (1996). Development and validation of workfamily conflict and family-work conflict scales. Journal of Applied Psychology, 81(4), 400-410. doi:10.1037/0021-9010.81.4.400

Office for National Statistics. (2015). UK Business: Activity, size and location: 2015. Retrieved from https://www.ons.gov.uk/businessindustryandtrade/business/activitysizeandlocation/bu $\underline{\text { lletins/ukbusinessactivitysizeandlocation/2015-10-06 }}$

Olesen, M. H., Thomsen, D. K., \& O’toole, M. S. (2015). Subjective well-being: Above neuroticism and extraversion, autonomy motivation matters. Personality and Individual Differences, 77, 45-49. doi:10.1016/j.paid.2014.12.033

Pope, C., Ziebland, S., \& Mays, N. (2000). Qualitative research in health care: Analysing qualitative data. $B M J, 320,114-116$.

Quality Assurance Agency. (2015). The UK Quality Code for Higher Education: a Brief Guide . Retrieved from London:

Ritchie, J., Spencer, L., \& O'Connor, W. (2003). Carrying out Qualitative Analysis. In J. Ritchie \& J. Lewis (Eds.), Qualitative Research Practice. London: Sage.

Ross, M., Grace, D., \& Shao, W. (2013). Come on higher ed ... get with the programme! A study of market orientation in international student recruitment. Educational Review, 65(2), 219-240. doi:10.1080/00131911.2012.659656 
Rothmann, S., \& Jordaan, G. M. E. (2006). Job demands, job resources and work engagement of academic staff in South African Higher Education Insitutions. SA Journal of Industrial Psychology, 32(4), pp87-96.

Saul, H. (2014, 4 June 2014). Universities receive 20,000 complaints from students 'demanding more' for $£ 9000$ fee. The Independent. Retrieved from http://www.independent.co.uk/student/universities-receive-20000-complaints-from$\underline{\text { students-demanding-more-for-9000-fee-9476384.html }}$

Siegrist, J. (1996). Adverse health effects of high-effort/low-reward conditions. Journal of Occupational Health Psychology, 1(1), 27-41.

Siegrist, J. (1998). Adverse health effects of effort-reward imbalance at work: theory, emperical support, and implications for prevention. In C. L. Cooper (Ed.), Theories of Organisational Stress (pp. pp190-204). Oxford: Oxford University Press.

Siegrist, J. (2001). A theory of occupational stress. In J. Dunham (Ed.), Stress in the workplace: past, Present and future. London: Whurr.

Siegrist, J., Falck, B., \& Joksimovic, L. (2005). The effects of effort-reward imbalance at work on health. In A.-S. G. Antoniou, C. L. Cooper, A.-S. G. Antoniou, \& C. L. Cooper (Eds.), Research companion to organizational health psychology. (pp. 430-440). Northampton, MA, US: Edward Elgar Publishing.

Siegrist, J., Starke, D., Chandola, T., Godin, I., Marmot, M., Niedhammer, I., \& Peter, R. (2004). The measurement of effort-reward imbalance at work: European comparisons. Social Science \& Medicine, 58(8), 1483-1499. doi:10.1016/S0277-9536(03)00351-4

Silverman, D. (2010). Doing Qualitative Research (3rd ed.). London: Sage.

Smith, K. M., Crookes, P. A., Else, F., \& Crookes, E. (2012). Scholarship reconsidered: implications for reward and recognition of academic staff in schools of nursing and 
beyond. Journal of Nursing Management, 20(2), 144-151. doi:10.1111/j.13652834.2011.01374.x

Szekeres, J. (2010). Sustaining student numbers in the competitive marketplace. Journal of Higher Education Policy \& Management, 32(5), 429-439. doi:10.1080/1360080X.2010.511116

Trudel, L., Vonarx, N., Simard, C., Freeman, A., Vézina, M., Brisson, C., . . Dugas, N. (2009). The adverse effects of psychosocial constraints at work: A participatory study to orient prevention to mitigate psychological distress. Work: Journal of Prevention, Assessment \& Rehabilitation, 34(3), 345-357.

Tsutsumi, A., \& Kawakami, N. (2004). A review of emperical studies on the model of effortreward imbalance at work: reducing occupational stress by implementing a new theory. Social Science \& Medicine, 59, pp2335-2359.

Tsutsumi, A., Takao, S., Mineyama, S., Nishiuchi, K., Komatsu, H., \& Kawakami, N. (2005). Effects of a supervisory education for positive mental health in the workplace: a quasiexperimental study. Journal Of Occupational Health, 47(3), 226-235.

UNESCO. (2015). Institute fo Statistics Data on Education. Retrieved from Retrieved from http://data.worldback.org:

Universities UK. (2014). The economic impact of higher education institutions in England. Retrieved from $\quad$ http://www.universitiesuk.ac.uk/policy-andanalysis/reports/Pages/economic-impact-higher-education-institutions-inengland.aspx:

van den Brink, M., Fruytier, B., \& Thunnissen, M. (2013). Talent management in academia: Performance systems and HRM policies. Human Resource Management Journal, 23(2), 180-195. doi:10.1111/j.1748-8583.2012.00196.x 
Van Yperen, N. W., Wörtler, B., \& De Jonge, K. M. M. (2016). Workers' intrinsic work motivation when job demands are high: The role of need for autonomy and perceived opportunity for blended working. Computers in Human Behavior, 60, 179-184. doi:10.1016/j.chb.2016.02.068

Warr, P. (1987). Work, unemployment, and mental health. New York, NY, US: Oxford University Press.

Williams, K. J., \& Alliger, G. M. (1994). Role stressors, mood spillover, and perceptions of work-family conflict in employed parents. Academy of Management Journal, 37(4), 837-868. doi:10.2307/256602

Winefield, A. H., Gillespie, N., Stough, C., Dua, J., Hapuarachchi, J., \& Boyd, C. (2003). Occupational stress in Australian university staff: Results from a national survey. International Journal of Stress Management, 10(1), 51-63. doi:10.1037/10725245.10 .1 .51

Winter, R., \& Sarros, J. (2002). The Academic Work Environment in Australian Universities: A motivating place to work? Higher Education Research \& Development, 21(3), 241258. doi:10.1080/0729436022000020751 